\title{
Manufacturing of GLS-Se glass rods and structured preforms by extrusion for optical fiber drawing for the IR region
}

\author{
Fernando Guzman $\odot$, ${ }^{\mathrm{a}, *}$ Christopher Craig, ${ }^{\mathrm{a}}$ Bruno Moog, ${ }^{\mathrm{a}}$ \\ Andrea Ravagli, ${ }^{\mathrm{b}}$ Katrina A. Morgan $\odot,{ }^{\text {a }}$ and Daniel W. Hewak ${ }^{\mathrm{a}}$ \\ ${ }^{a}$ Optoelectronics Research Centre, Southampton, United Kingdom \\ ${ }^{\mathrm{b}} \mathrm{Schott}$ AG, Mainz, Germany
}

\begin{abstract}
Chalcogenide glasses are amorphous solid materials formed from chalcogen elements bonding with metals to form typically in binary or tertiary compounds. One family of chalcogenide glasses, based on gallium and lanthanum sulphides, possesses properties important for the infrared (IR) window transmissions and IR applications; these include thermal stability, high solubility of rare earth ions, low phonon energy and high laser damage threshold. Efforts have been made to produce new chalcogenide glasses that can extend the IR transmission window further into the IR. Work has led to the successful melting of a selenium-modified gallium lanthanum sulphide (GLS-Se) glass that can transmit up to $15 \mu \mathrm{m}$, however these glasses have, to date, only been demonstrated in bulk glass form. We aim to develop processes for the fabrication of chalcogenide optical fiber to exploit the properties of chalcogenide glasses. Several potential applications include sensing for the civil, medical, and military areas, as these materials offer transmission over much of the molecular fingerprint region ( 2 to $25 \mu \mathrm{m}$ ). The aim of our work is to understand and control the thermal properties and stability of GLS-Se glasses without compromising their optical properties, in order to produce transparent glass rods and demonstrate the feasibility in fabrication for structured optical preforms by extrusion, as the first step to achieve optical fiber from GLS-Se glass. (C) 2021 Society of Photo-Optical Instrumentation Engineers (SPIE) [DOI: 10.1117/1.OE.60.4.045101]
\end{abstract}

Keywords: chalcogenide; glass; manufacturing; infrared; preform; extrusion.

Paper 20210027 received Jan. 7, 2021; accepted for publication Mar. 16, 2021; published online Apr. 8, 2021.

\section{Introduction}

Extrusion is a well-known process for metal and plastic manufacturing where rods, tubes, or complex structures have been routinely produced. ${ }^{1}$ In 1970, Roeder ${ }^{2}$ studied extrusion in the glass field. Before Roeder, the lack of use of extrusion for glass materials was due to the fact that most of the shaping glass methods were based on casting, blowing, or rolling. ${ }^{3}$ Nevertheless, the need for new kinds of glasses with specialized compositions is becoming crucial ${ }^{4}$ and with that comes the need for new glass processing methods. Many novel glasses, as a consequence of their compositions and relatively small glass formation regions and propensity to crystallize when heated, are difficult to shape by these traditional methods. In this regard, extrusion is particularly suitable for glasses with a strong tendency to crystallization. ${ }^{5}$

As optical fiber technology advances, the need for different type of fibers with complicated geometries ${ }^{6}$ and/or produced from novel optical materials ${ }^{7}$ increases, accompanied by a demand to produce different shapes of preforms with compositions that remain stable enough on heating to be drawn into fiber. One method explored was capillary stacking, ${ }^{8}$ which consumes a lot of human effort with little tolerance for assembly errors. With this need in mind and applying the efforts of Roeder, we have explored the extrusion process applied to selenium-modified gallium lanthanum sulphide (GLS-Se) glass, demonstrating that it is a reliable method of fabrication of structured chalcogenide glass preforms ${ }^{9}$ and that the potential applications can be realized. ${ }^{10}$

*Address all correspondence to Fernando Guzman, f.a.guzman-cruz@soton.ac.uk 
The glass extrusion results described in this work are focussed on GLS-Se-based glasses. Previously, a range of different chalcogenide glass compositions have been used to produce optical preforms by a variety of methods, including extrusion. ${ }^{11}$ The aim of this current work is to prove that this method is reliable and does not compromise the quality of the samples based on the new GLS-Se compositions. Past work on the drawing of some chalcogenide-based glasses has benefited indirectly from residual oxides in the glass ${ }^{12}$ or by intentional doping with oxides, as in gallium lanthanum sulphide oxide compositions ${ }^{13}$ where the oxygen content acts as a thermal stabilizer. ${ }^{14}$ With GLS-Se compositions, however, oxides compromise the infrared (IR) transmission thus the challenge faced here is to produce rods and structured preforms, which are oxygen free.

In summary, to understand how to manufacture glass rods or structured (core-clad) preforms from any glass composition using the flexibility of the extrusion process and the possible implications of it, two main factors: (a) the thermal characteristics of the glass to be extruded, and (b) the details of the time and temperature utilized in the process must be studied. Considering both factors, we sought to exploit the thermal and mechanical properties of the glass in order to reshape it into the desired form without compromising the desirable characteristics of the bulk glass samples. A key requirement is avoiding crystallization, as this increases transmission losses in the glass and renders the material opaque to light delivery. This work shows that when properly configured, we can effectively use the extrusion process to produce structured or solid rods of GLS-Se glass, which can be drawn into optical fiber. ${ }^{15}$

\section{Glass Billets Production for Extrusion}

GLS-Se glass billets are produced following the established process of raw material mixing, meltquenching, and annealing. ${ }^{16}$ The glasses are formed from gallium sulphide $\left(\mathrm{Ga}_{2} \mathrm{~S}_{3}\right)$, lanthanum sulphide $\left(\mathrm{La}_{2} \mathrm{~S}_{3}\right)$, and gallium selenide $\left(\mathrm{Ga}_{2} \mathrm{Se}_{3}\right)$, with this latter component varied through each melt (20,30, and $35 \mathrm{~mol}$. \%). To obtain the desired dimensions, the melting took place in cylindrical high purity vitreous carbon crucibles. Previous studies ${ }^{17}$ have shown that in the spectral region between 4 and $8 \mu \mathrm{m}$, there are no characteristic carbon absorption peaks ${ }^{18}$ which is due to the inertness of the vitreous carbon crucibles validating the use of this type of crucible for the glass melting. The in-house built extrusion apparatus is designed to accommodate glass billets between 20 and $23 \mathrm{~cm}^{3}$ of volume, with a diameter of up to $30 \mathrm{~mm}$ as shown in Fig. 1.

\subsection{Billets Polishing for Extrusion}

After annealing the samples, further processing consists of lapping and polishing to smooth the end faces of the samples for further measurements and to remove any impurities and

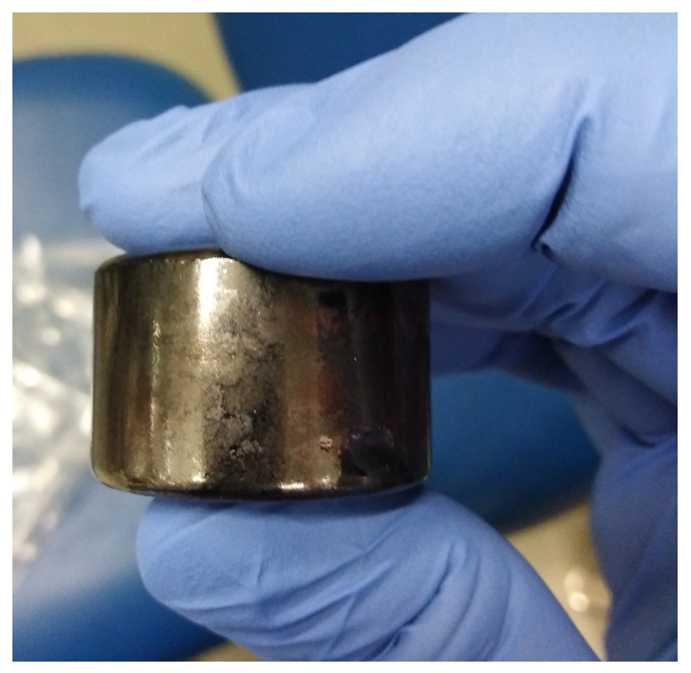

Fig. 1 GLS-Se glass billet for extrusion. 


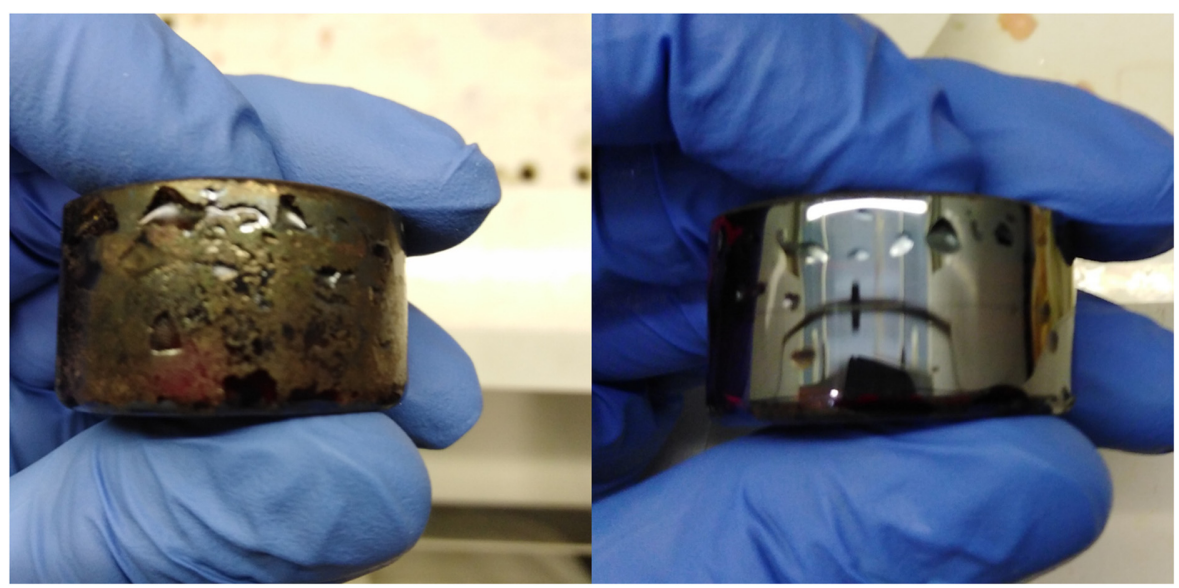

Fig. 2 Polished cylindrical surface of a billet.

imperfections on the surface. GLS-Se glasses contain sulphur which may react with water, therefore ethanediol is used as the lubricant. Three different sizes of alumina powder are used $(9,1$, and $0.3 \mu \mathrm{m}$ ) to give the samples an optical finish. In addition to the end faces, the cylindrical surface was also polished using diamond films up to a $1 \mu \mathrm{m}$ finish (Fig. 2). Polishing the end faces and cylindrical surface of each billet ensured that any possible surface impurities or imperfections in the glass were eliminated, to avoid any induced crystallization as a result of preexisting heterogeneous nuclei. ${ }^{19}$

\section{Extrusion of GLS-Se Glass}

This work has focused on the use of the direct extrusion method, ${ }^{2}$ adapting it for the requirements of chalcogenide glasses. For metal alloys or polymers, the way to obtain a well-defined extruded material exploits the material plasticity through a carefully designed die that allows the material to easily flow solely by applying pressure. ${ }^{20}$ In this work, we show that as the material to be extruded is glass, an important aspect to consider is the viscosity as a function of temperature. Heat needs to be supplied to the billet to be able to perform the process ${ }^{21}$ as the glass resides in a super cooled state unless the temperature is increased. ${ }^{22}$ Even though heating is required, the extrusion process can be performed at a temperature below the softening point $(7.6 \mathrm{dPa} \cdot \mathrm{s})$, which is a characteristic of all glasses ${ }^{23}$ by careful control of the pressure and timing of the process. ${ }^{24}$ Roeder ${ }^{2,5}$ suggests that when heating up the glass to a temperature suitable for extrusion, it is not necessary to reach the temperatures that promote nucleation and crystallization; however for GLS-Se glass compositions, a temperature above the $T_{g}$ is needed, therefore some nucleation may take place. As previously observed by Roeder, ${ }^{2}$ provided extrusion takes place below the onset of crystallization and the cooling of the glass after exiting the die is greater than the critical cooling rate, crystallization can be avoided.

\subsection{Extrusion Apparatus}

The extrusion apparatus utilized in this work consists of the following elements, shown in Fig. 3: (a) piston, to produce a direct extrusion and the load required; (b) ceramic shield, to maintain the heat of the entire apparatus; (c) heating elements, where one supplies heat to the main body of the billet container of the apparatus and the other supplies heat directly to the die, this latter heating element is placed just below the die and helps to maintain the temperature of the exiting extruded material; (d) thermocouples, connected directly to a thermal controller and the heating elements, which will maintain the set temperature; (e) carbon body, which is heated up by the power resistors and holds the container with the billet; (f) billet container, divided in three parts: sleeve, lid, and the die itself. 


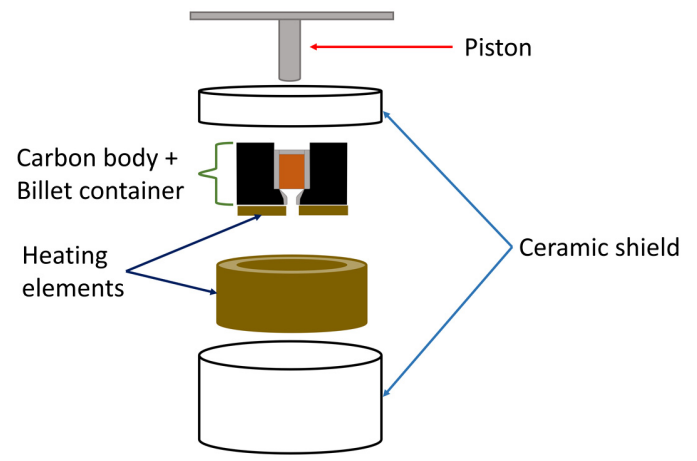

Fig. 3 Schematic of the in-house built extrusion apparatus assembly.
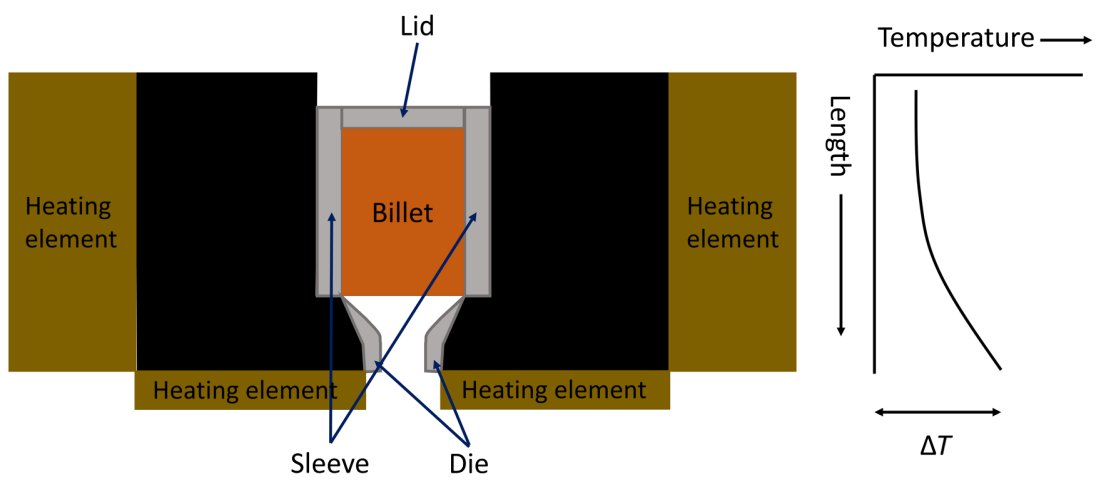

Fig. 4 Cross-section of the billet assembled in the body container (sleeve, lid, and die); and temperature profile of the extrusion apparatus.

The sleeve, lid, and die are produced from 303 grade stainless stee ${ }^{25}$ by conventional machining followed by laser polishing. The sleeve has an inner diameter of 29 to $30 \mathrm{~mm}$ and a height of $35 \mathrm{~mm}$, the die has a smooth profile, reducing down to an aperture of $10 \mathrm{~mm}$, and the lid has a diameter that fits the sleeve with a thickness of $5 \mathrm{~mm}$. The cross-sectional area of the assembly is visualized in Fig. 4. It shows how the billet temperature profile behaves with respect to its two independent heating elements, which heats the whole container. The bottom heating element (closer to the die) produces a slight temperature difference $(\Delta T)$ with respect to the main body heating element. This is needed to ensure that the extruded material keeps flowing out of the die and avoids any possible cooling that could affect the extrusion at the die aperture.

\subsection{Extrusion Apparatus Considerations}

Billets after polishing benefit from cleaning by a 1-h ultrasonic bath to remove any trace of ethanediol. The billet container (die, sleeve, and lid) is also cleaned in isopropanol for $1 \mathrm{~h}$ to remove any residual grease left during machining. Dies are polished by a laser machine, but as seen in Fig. 5 it is not a completely flat surface, this will result in some features on the glass surface that are detrimental for further processing (i.e., fiber drawing). These imperfections are avoidable through further polishing of the die but for the purpose of this work, dies were sufficiently smooth to enable the process to be tested and optimized.

\subsection{GLS-Se Extrusion for Rods with Single Compositions and Structured Preforms}

The restriction of the temperature to below the onset of crystallization establishes the path to follow to obtain the correct temperature for the extrusion of transparent and crystals-free preforms. Our approach to optimizing this process was to choose a temperature low enough to avoid 


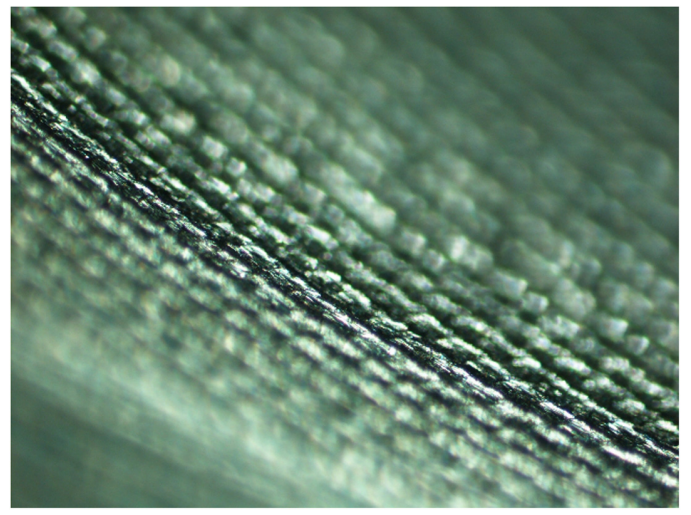

Fig. 5 Microscope image of the die surface used for extrusion.

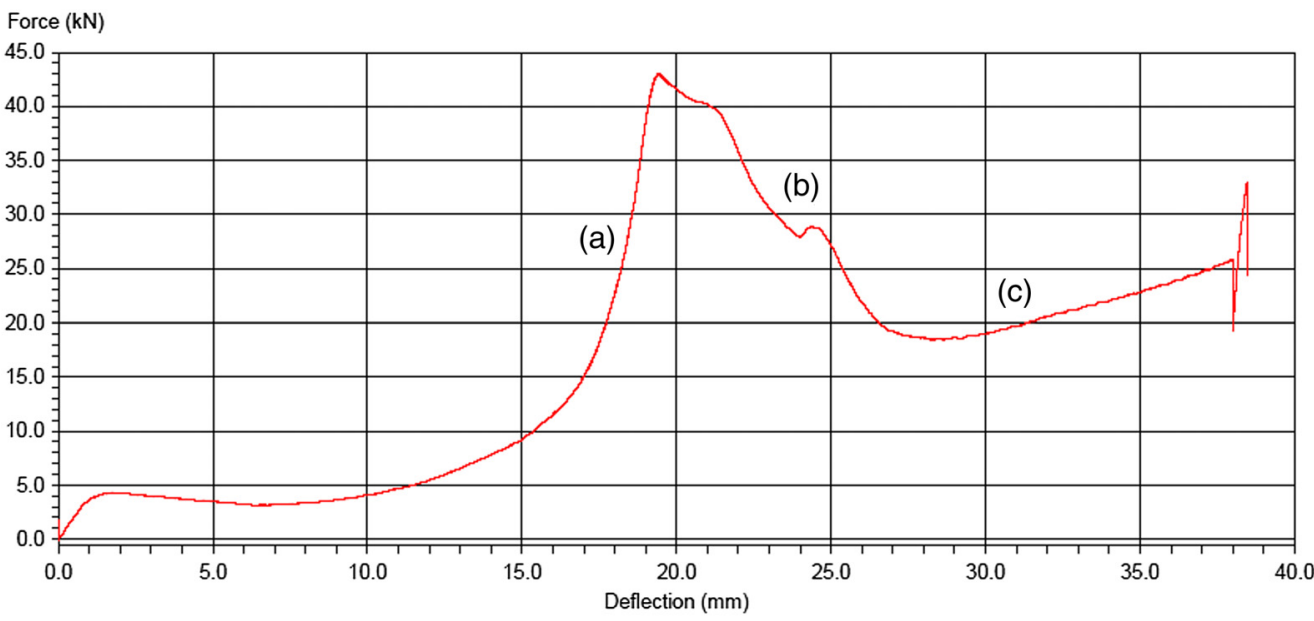

Fig. 6 Successful extrusion with temperature increasing steps, where (a) load sharply rise, (b) load decreased as temperature increases, and (c) constant and stable load.

crystallization but sufficient to decrease the viscosity of the glass to approximately $6.5 \mathrm{dPa} \cdot \mathrm{s}$. The first successful trials included a progressive increase in temperature in intervals of $5^{\circ} \mathrm{C}$, when the load started to raise and until the load descended to a stable value that could keep the extrusion process flowing consistently (Fig. 6).

From these preliminary extrusion trials, with temperature increasing in small steps, the maximum temperature that allowed a continuous extrusion and glass rods without crystals was obtained. The maximum temperature sets on the temperature controller were $610^{\circ} \mathrm{C}$ for the bottom heating element and $600^{\circ} \mathrm{C}$ for the main heating element. Every successfully extruded rod had a uniform diameter of $10 \mathrm{~mm} \pm 0.02$ over a typical total extruded length of $26 \mathrm{~cm}$, which confirms the stability of the extrusion process and the reliability of the fabrication itself.

For structured (core-clad) preforms, glass compositions containing $\mathrm{Ga}_{2} \mathrm{Se}_{3} 30$ and $35 \mathrm{~mol} . \%$ were selected, as they present comparable but sufficient different refractive indices, to ensure light confinement to the core, and to allow co-extrusion matching thermal properties. ${ }^{5}$ Billets were prepared with the same steps that proved to be essential for a successful single material extrusion. The two glass samples were placed in the billet container and every step was reproduced, following the procedure for a single material. The load curve did not present a big difference compared to single composition extrusions. What needed to be proven was that the coextrusion process behaves similarly to a single composition extrusion glass flow and produces a smooth and continuous core-clad interface (Fig. 7) without any scattering from introduced impurities or induced crystallization during the process (Fig. 8). Development of this technique with GLS-Se glasses opens the possibility to be used for other GLS-based glass compositions. 


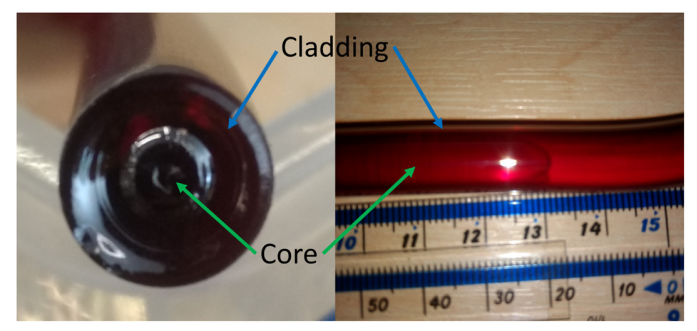

Fig. 7 Successful structured preform after co-extrusion.

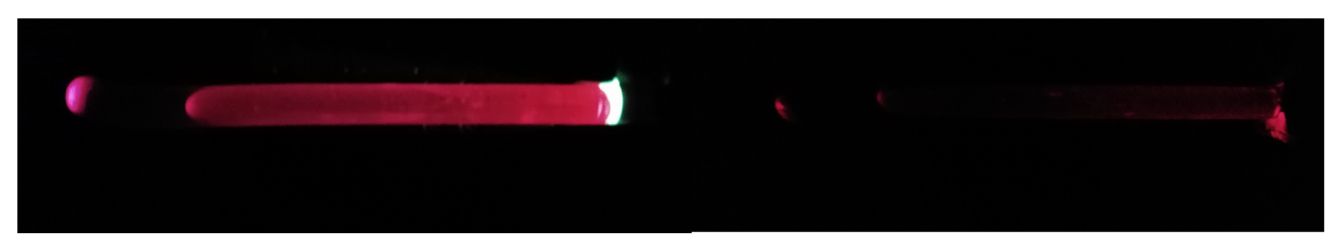

(a)

(b)

Fig. 8 Structured preforms under a while light source showing the scattering in the core-clad interface, where (a) shows a heavily scattering preform, as no polishing was performed and (b) scattering was suppressed, as all samples were polished to reduce impurities in the interface.

\subsection{Improvements during the Development of Successful GLS-Se Extruded Rods and Preforms}

During the course of these experiments, 28 extrusion trials were undertaken. Each extrusion attempt provided feedback about the success of the process details and represented an opportunity to improve the quality of the samples and the parameters involved (i.e., extrusion temperature) and optimize existing steps (i.e., polishing). For example, Figs. 9-11 clearly show the difference in quality between extruded samples using $630^{\circ} \mathrm{C}$ (high temperature, viscosity $6.5 \mathrm{dPa} \cdot \mathrm{s}$ ) and $610^{\circ} \mathrm{C}$ (low temperature, viscosity $6 \mathrm{dPa} \cdot \mathrm{s}$ ), where this difference of just $20^{\circ} \mathrm{C}$ eliminated the chances of crystallization in conjunction with the impurities reduction due to the polishing steps.

\section{Results}

The first part of this work shows the initial experiments that confirm extrusion is a compatible process with GLS-Se glasses. Afterward, a full study was undertaken to further prove the suitability of extrusion, and the extruded glass properties are examined postprocess. To assess the

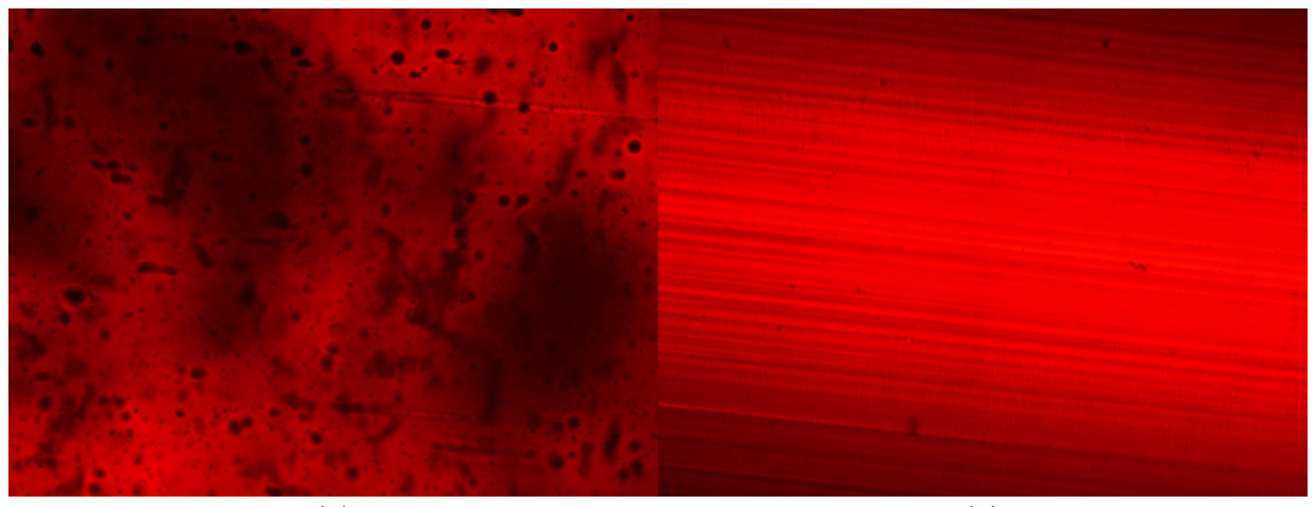

(a)

(b)

Fig. 9 Surface extruded quality, showing the effects of using (a) $630^{\circ} \mathrm{C}$ and (b) $610^{\circ} \mathrm{C}$. 


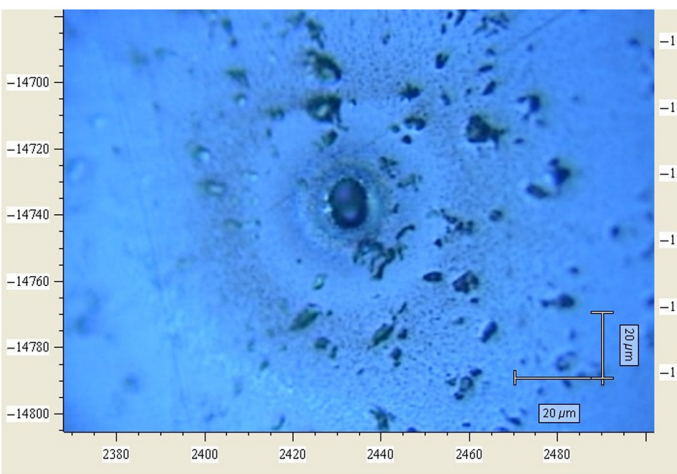

(a)

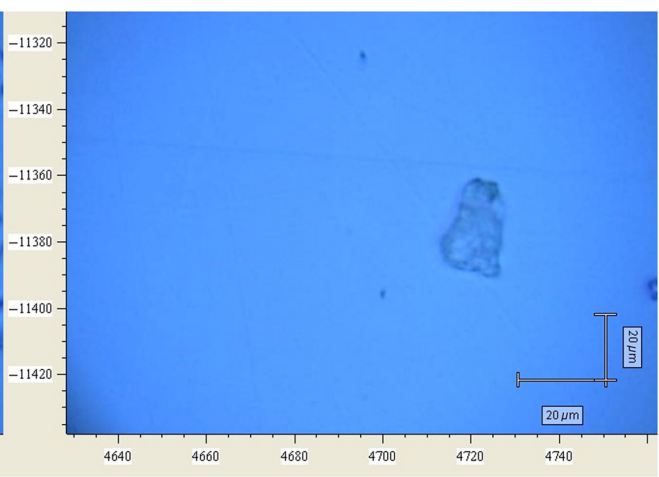

(b)

Fig. 10 Difference in the glass quality, due to the effects of using (a) $630^{\circ} \mathrm{C}$ and (b) $610^{\circ} \mathrm{C}$.

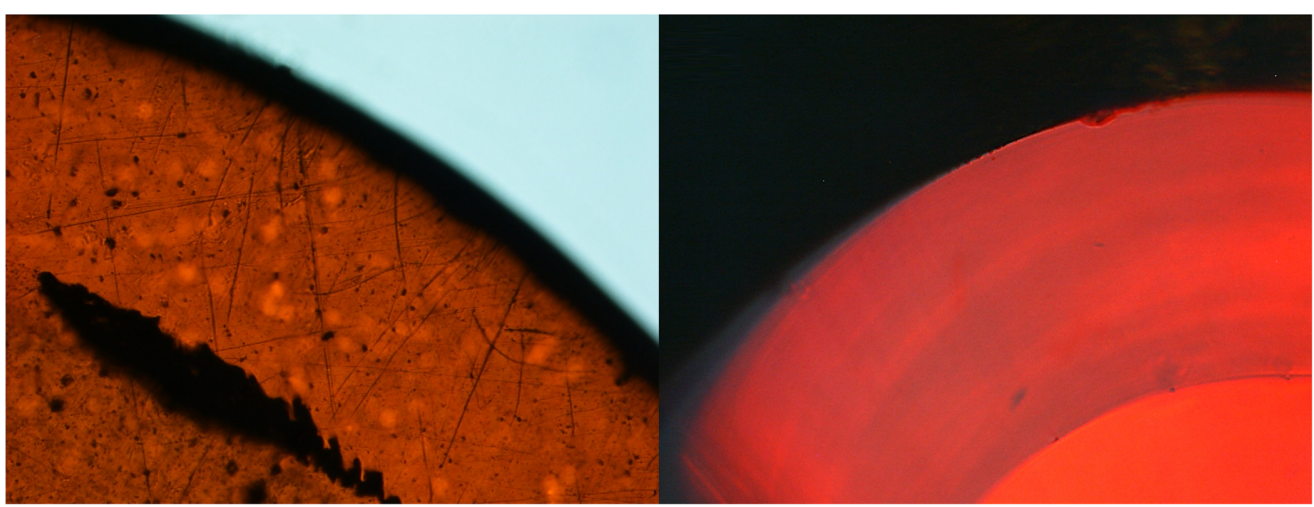

(a)

(b)

Fig. 11 Structured preform interface differences between extruded samples, showing the importance of the cleaning steps, where (a) shows impurities and (b) is cleaner.

glasses quality after extrusion, Raman spectroscopy was used to assess structural changes and thermal analysis provided information about crystal nucleation. Measurement of refractive index before and after extrusion provided further evidence of changes to the glass and finally optical spectroscopy directly provided information on transmission changes, verifying if absorption or scattering losses were introduced. With this characterization, it is demonstrated that the extrusion process is a viable solution for preform fabrication with these materials, as their desirable characteristics are maintained after the extrusion process, ensuring their properties can be exploited also in form of an optical fiber for multiple applications.

\subsection{Thermal Characterization of GLS-Se Extruded Glass}

An overall guiding principle for the extrusion of glasses prone to crystallization is to decrease the time of the process to a minimum. Accordingly, the extrusion speed was increased to $0.5 \mathrm{~mm} / \mathrm{min}$, which reduced the time of exposure of the glass to heat from $6 \mathrm{~h}$ to approximately $1 \mathrm{~h}$. The importance of this change is demonstrated by the observation that the initial extrusions affected the thermal behavior of the glass (Figs. 12 and 13), obtained with the Perkin Elmer Diamond TG-DTA at a heating ramping rate of $10^{\circ} \mathrm{C} / \mathrm{min}$ and using $30 \mathrm{mg}$ samples. These figures show that the exothermic crystallization peak has a higher amplitude and is broader compared to that of the bulk samples before the extrusion process.

Although extruded GLS-Se glasses present almost the same characteristic temperatures as bulk glass samples, the changes in the features of these curves, such as the stronger crystallization peak, suggest that some material changes are occurring during extrusion which could affect other bulk properties such as heat capacity. ${ }^{19}$ For the most part during extrusion, the 


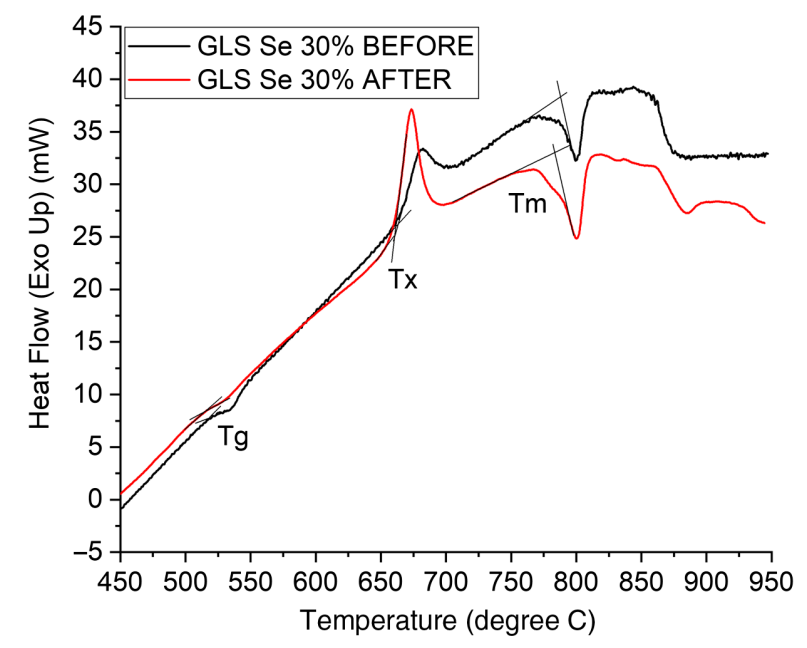

Fig. 12 DTA curve for GLS-Se glass samples with $\mathrm{Ga}_{2} \mathrm{Se}_{3} 30 \mathrm{~mol}$. \% before and after extrusion.

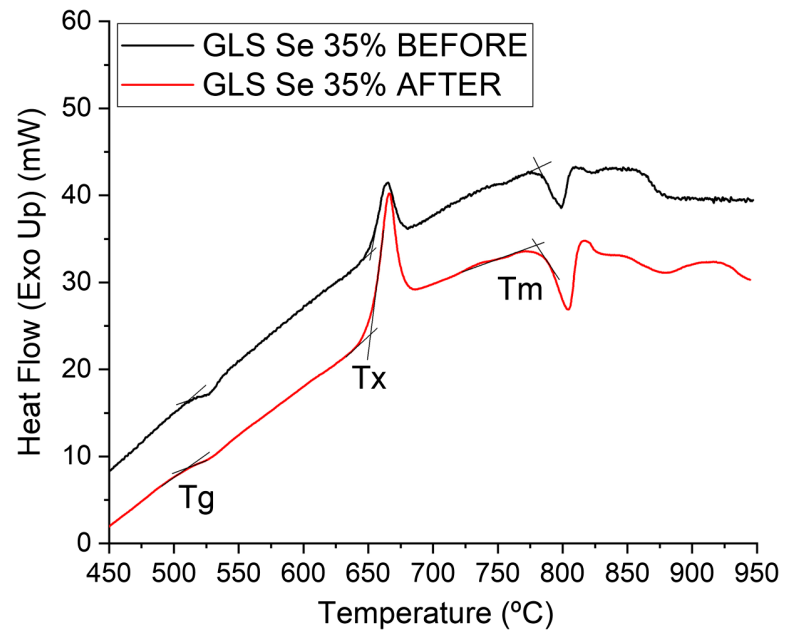

Fig. 13 DTA curve for GLS-Se glass samples with $\mathrm{Ga}_{2} \mathrm{Se}_{3} 35 \mathrm{~mol}$. \% before and after extrusion.

Table 1 Thermal characterization for GLS-Se glass samples before and after extrusion.

\begin{tabular}{lccccccc}
\hline \hline & \multicolumn{3}{c}{ Bulk } & & \multicolumn{3}{c}{ Extruded } \\
\cline { 2 - 4 } \cline { 6 - 8 } Composition & $T_{g}\left({ }^{\circ} \mathrm{C}\right)$ & $T_{x}\left({ }^{\circ} \mathrm{C}\right)$ & $T_{c}\left({ }^{\circ} \mathrm{C}\right)$ & & $T_{g}\left({ }^{\circ} \mathrm{C}\right)$ & $T_{x}\left({ }^{\circ} \mathrm{C}\right)$ & $T_{c}\left({ }^{\circ} \mathrm{C}\right)$ \\
\hline GLS-Se 20\% & 519 & 678 & 802 & & 512 & 679 & 805 \\
GLS-Se 30\% & 517 & 663 & 786 & & 515 & 661 & 783 \\
GLS-Se 35\% & 511 & 652 & 782 & 510 & 651 & 780 \\
\hline \hline
\end{tabular}

characteristic thermal properties for different contents of Se are maintained, ${ }^{26}$ as shown in Table 1. The difference between the onset of crystallization of bulk samples produced in this work and previous studies ${ }^{18}$ is of maximum $1 \%$, each temperature in this work presents a $\pm 2{ }^{\circ} \mathrm{C}$ approximation within temperatures of the same composition.

Measurement of viscosity through thermomechanical analysis (TMA) showed that the characteristic viscosity of GLS-Se extruded glass was maintained, and the softening point corresponded to previous study ${ }^{27}$ with a maximum difference of $1 \%$ between values of the same 
Table 2 Temperature at the softening point for GLS-Se glass samples before and after extrusion.

\begin{tabular}{lcc}
\hline & Bulk $^{27}$ & Extruded \\
\cline { 2 - 3 } Composition & Softening point $\left({ }^{\circ} \mathrm{C}\right)$ & Softening point $\left({ }^{\circ} \mathrm{C}\right)$ \\
\hline GLS-Se $20 \%$ & 623 & 616 \\
GLS-Se 30\% & 581 & 583 \\
GLS-Se 35\% & - & 588 \\
\hline \hline
\end{tabular}

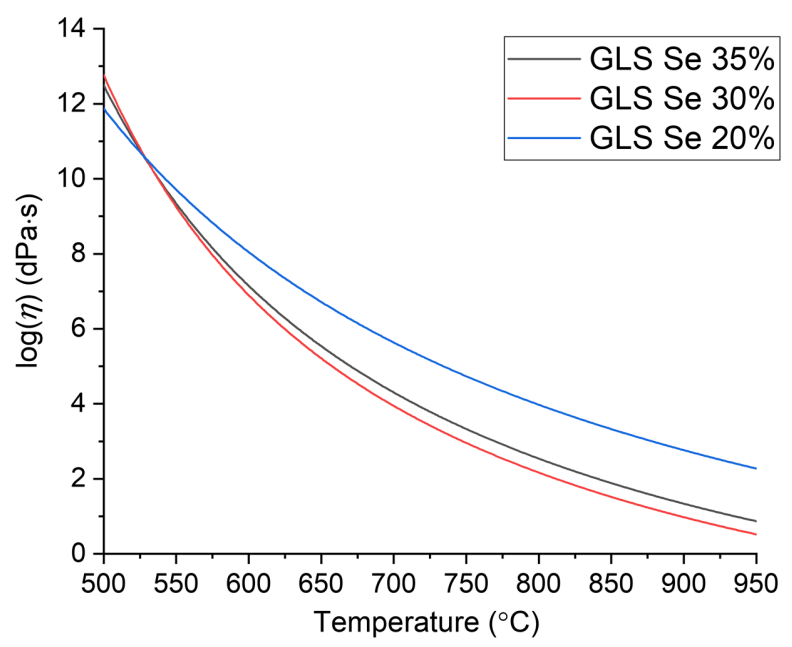

Fig. 14 Viscosity curves for different GLS-Se extruded glasses. Note: for visual clarity no error bars are displayed as the standard deviation showed a maximum error of $0.5 \%$.

composition, as seen in Table 2. The softening point for each composition corresponds to a viscosity of $7.6 \mathrm{dPa} \cdot \mathrm{s}$.

Increasing the $\mathrm{Ga}_{2} \mathrm{Se}_{3}$ content, in the first instance, decreases the softening point but as the concentration increases further it starts increasing again, as it tends to a maximum in the phases of $\mathrm{Ga}_{2} \mathrm{Se}_{3},{ }^{28}$ as shown in Fig. 14. To obtain a standardized and reliable viscosity curve, the ISO 7884-4 norm can be applied to the three-point bending technique commonly used in TMA. The viscosity as a function of temperature can be extracted using Eqs. (1) and (2). ${ }^{29}$

$$
I_{c}=\frac{h^{3} b}{12}
$$

where $h$ is the thickness and $b$ is the width of the sample, respectively, in millimeters.

$$
\eta=681 \frac{I_{s} \Delta t m}{I_{c} \Delta f},
$$

where $\eta$ is the viscosity in $\mathrm{dPa} \cdot \mathrm{s}, \Delta f$ is the difference in position during the measuring time $\Delta t$ in seconds, $I_{c}$ is the cross-sectional moment of inertia in millimeters to the fourth power, $m$ is the mass of the load in grams, and $I_{s}$ the span in millimeters. After using the standard ISO 7887-4, the viscosity data were fitted to the Vogel-Fulcher-Tammann equation: ${ }^{30}$

$$
\log (\eta)=k+\frac{a}{T-b}
$$

where $T$ is the temperature of the sample; $k, a$, and $b$ are the fitting parameters. The curves were plotted from the transition temperature according to the DTA to $950^{\circ} \mathrm{C}$. These viscosity curves, in 
addition to the data obtained by DTA, are the basis for establishing the parameters for fiber drawing of the extruded GLS-Se glass-based rods and structured preforms.

\subsection{Optical and Material Characterization for Extruded Glass}

Ultimately, extrusion will only be a viable process for chalcogenide glass if optical transparency can be maintained. The results presented in this section directly measure the optical transmission of our glasses before and after extrusion. A disk of 1-mm thickness was cut from each extruded rod and polished to an optical finish. Optical transmission was measured using a UV-VIS-NIR (Cary-500) and a FTIR (Cary-670) spectrometers in the range of $500 \mathrm{~nm}$ to $15 \mu \mathrm{m}$. The optical transmission for the extruded samples corresponds to what is measured on the bulk samples, ${ }^{17}$ with a maximum difference of $5 \%$ for the sample with $\mathrm{Ga}_{2} \mathrm{Se}_{3}$ (35 mol. \%), considering that some transmission loss due to reflection and scattering produced by imperfections in the polishing might occur. Also, there is a loss from 10 to $12 \mu \mathrm{m}$, which corresponds to an absorption due to oxide impurities, ${ }^{31}$ that could have been produced as the extrusion is not in a purged environment and above the $T_{g}$ where glass can react with oxygen ${ }^{32}$ this would explain the difference between pre-extruded and extruded glass samples as seen in Fig. 15.

The refractive index was measured using an ellipsometer (Woollam ${ }^{\circledR}$ M-2000) from $370 \mathrm{~nm}$ to $1 \mu \mathrm{m}$, the Sellmeier Eq. (4) was used to fit the obtained values, ${ }^{33}$ where $n(\lambda)$ is the wavelength-dependant refractive index, $\lambda$ is the wavelength, and $A, A_{1}, B, B_{1}, C$, and $C_{1}$ are the fitting parameters. Refractive index shows a change as the amount of $\mathrm{Ga}_{2} \mathrm{Se}_{3}$ is increased, which corresponds to the previously studied bulk samples ${ }^{16}$ as the polarization of the glass is modified by modifying the composition ${ }^{34}$ (Fig. 16). Error bars were calculated using Origin ${ }^{\circledR}$ through the standard deviation and have a maximum error of $0.2 \%$.

$$
n(\lambda)^{2}=\frac{A \lambda^{2}}{\lambda^{2}-A_{1}}+\frac{B \lambda^{2}}{\lambda^{2}-B_{1}}+\frac{C \lambda^{2}}{\lambda^{2}-C_{1}}+1
$$

To verify that the transmission obtained was from an amorphous phase, Raman spectroscopy was performed in each composition of the extruded rods (Renishaw Invia system, laser $=532 \mathrm{~nm}$, MAX power $43 \mathrm{~mW}$ ). Each of the spectra was normalized to its highest peak value $\left(225 \mathrm{~cm}^{-1}\right)$ to compare the peaks displacement between samples. It was confirmed that extrusion does not produce crystallization and maintains the amorphous phase of the glass as no sharp peaks were found in the extruded rods. The peak at $325 \mathrm{~cm}^{-1}$ of $\mathrm{Ga}_{2} \mathrm{~S}_{3}$, which corresponds to the $\mathrm{GaS}_{4}$ tetrahedra vibrations overlapping with $\mathrm{LaS}_{8}$ vibrations, ${ }^{35}$ decreases as expected when the amount of $\mathrm{Ga}_{2} \mathrm{Se}_{3}$ increases. The peak at $225 \mathrm{~cm}^{-1}$ shifts to the left, toward

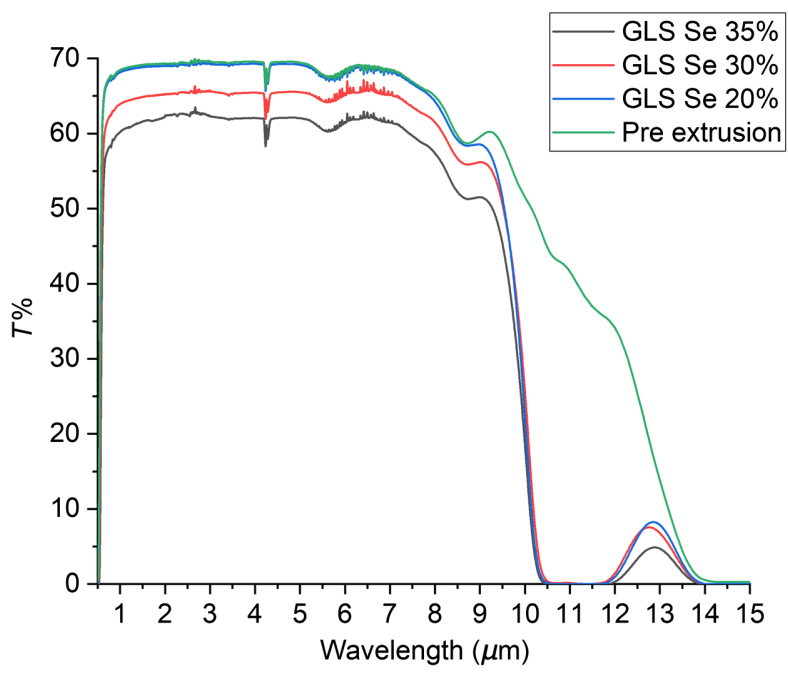

Fig. 15 Transmission spectra of the extruded glasses. Note: spectra not corrected for Fresnel reflections, the pre-extrusion spectrum corresponds to a $\mathrm{Ga}_{2} \mathrm{Se}_{3} 20$ mol. \% sample. 


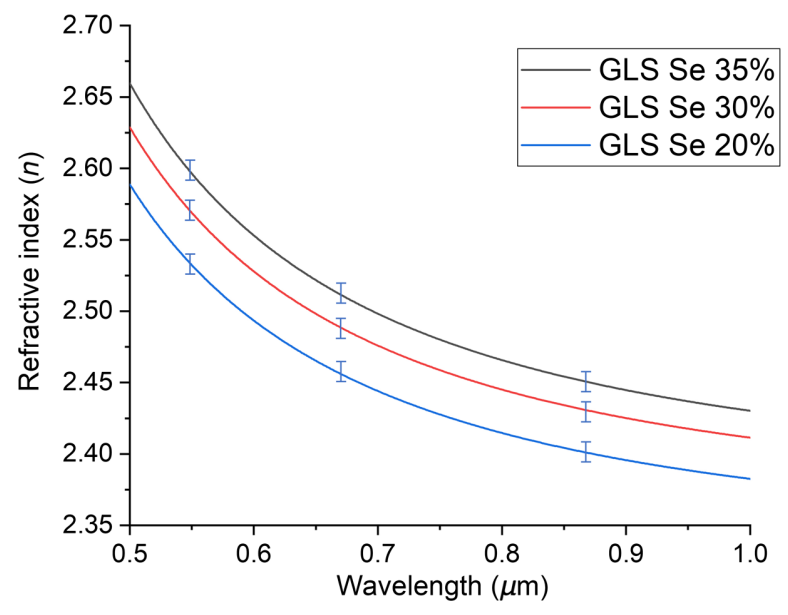

Fig. 16 Refractive index of the extruded glasses.

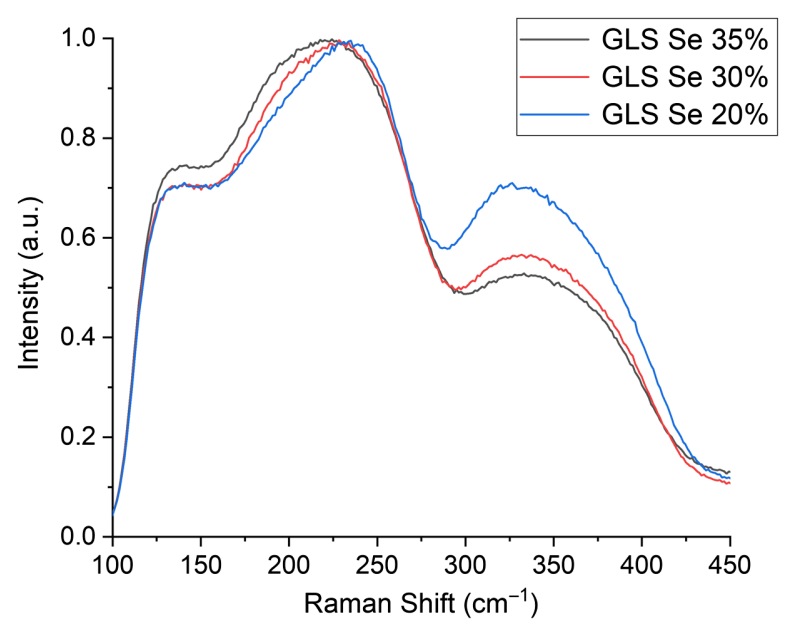

Fig. 17 Normalized Raman spectra of the extruded glasses.

$200 \mathrm{~cm}^{-1}$, with a higher amount of $\mathrm{Ga}_{2} \mathrm{Se}_{3}$ in the composition, as less $\mathrm{GaS}_{4}$ tetrahedral vibrations are active with this composition. ${ }^{36}$ Finally, the peak shoulder at $150 \mathrm{~cm}^{-1}$ corresponds to $\mathrm{La}_{2} \mathrm{~S}_{3}$ as is the only compound amount to remain constant through all three samples ${ }^{28,37,38}$ (Fig. 17). This analysis confirmed the amorphous nature of the extruded samples.

\section{Conclusions}

The thermal properties of the family of GLS-Se glasses can be exploited as predicted in previous studies, and this opens the possibility of producing glass rods and structured preforms for fiber drawing. This helps us to get closer to achieving the desired goal of obtaining optical fiber from these chalcogenide glasses to further exploit their properties. This study shows that moulding glass, in this case extruding, is not a simple and straightforward process. The intrinsic characteristics of the glasses indicate the parameters that might be useful for the process (i.e., softening point) but deny the possibility of predicting the behavior of the glass through every step taken. A complete methodology was developed to be able to extrude GLS-Se glass rods and preforms, throughout a combination of a literature review and an experimental approach. This study also shows that the optical, thermal, and mechanical properties of the extruded glasses correspond to the ones already demonstrated in their bulk form. Optically, there was an effect of having less transmission (up to 5\%) and a loss between 10 and $12 \mu \mathrm{m}$, which could mean that during 
extrusion there might be some mass loss resulting in a reduction in Se and an increase in oxygen contents due to the unpurged extrusion apparatus. Future work might include isolating or modifying the extrusion apparatus to further improve the quality of the extruded glass, using a different type of material for the billet container and adding steps during the process to keep impurities to a minimum level.

\section{Acknowledgments}

We acknowledge the contribution of Ed Weatherby for technical support, Nick White for assistance with extrusion, and Paul Frampton for providing glass blowing. This work was sponsored in part by Consejo Nacional de Ciencia y Tecnología (CONACyT) (Award No. 739108) and the Faculty of Physical Sciences and Engineering, Southampton. Chalcogenide glass research at Southampton is also supported through the Engineering and Physical Sciences Research Council (EPSRC) through research Grant EP/M015130/1, Manufacturing and Application of Next Generation Chalcogenides. The authors declare no conflicts of interest.

\section{References}

1. C. E. Pearson and R. N. Parkins, The Extrusion of Metals, Chapman \& Hall, CRC Press, London (1960).

2. E. Roeder, "Extrusion of glass," J. Non-Cryst. Solids 5(5), 377-388 (1971).

3. W. A. Weyl and E. C. Marboe, The Constitution of Glasses: Fundamentals of the Structure of Inorganic Liquids and Solids, Interscience Publishers (1962).

4. A. K. Singh, "A short over view on advantage of chalcogenide glassy alloys," J. Non-Oxide Glasses 3, 1-4 (2012).

5. E. Roeder, "Flow behaviour of glass during extrusion," J. Non-Cryst. Solids 7(2), 203-220 (1972).

6. J. L. Adam and X. Zhang, Chalcogenide Glasses: Preparation, Properties and Applications, Woodhead Publishing, Elsevier, Cambridge (2014).

7. B. G. Aitken et al., "Chalcogenide glass for low viscosity extrusion and injection molding," US20060257097A1 (2006).

8. J. C. Knight et al., "All-silica single-mode optical fiber with photonic crystal cladding," Opt. Lett. 21(19), 1547-1549 (1996).

9. T. M. Monro et al., "High nonlinearity extruded single-mode holey optical fibers," in Opt. Fiber Commun. Conf., Anaheim, California (2002).

10. V. V. R. K. Kumar et al., "Extruded soft glass photonic crystal fiber for ultrabroad supercontinuum generation," Opt. Express 10(25), 1520-1525 (2002).

11. A. Bornstein, N. Croitoru, and E. Marom, "Chalcogenide infrared glass fibers," Proc. SPIE 0320, 102-105 (1982).

12. A. B. Seddon, D. Furniss, and A. Motesharei, "Extrusion method for making fiber optic preforms of special glasses," Proc. SPIE 3416, 32-42 (1998).

13. X. Feng et al., "Nonsilica glasses for Holey fibers," J. Lightwave Technol. 23, 2046-2054 (2005).

14. M. Vlček et al., "Influence of oxygen traces on physical properties of glassy $\mathrm{GeSe}_{2}$," J. Mater. Sci. 22(6), 2119-2123 (1987).

15. F. Guzman et al., "GLS-Se optical fibre from extruded glass structured preforms and rods for the IR region," Opt. Mater. Express 11(1), 157-170 (2021).

16. A. Ravagli et al., "Ga-La-S-Se glass for visible and thermal imaging," Adv. Opt. Technol. 6(2), 131-136 (2017).

17. A. Ravagli, "Development of visible-to-LWIR multispectral chalcogenide glasses," University of Southampton (2018).

18. M. F. Churbanov, "High-purity chalcogenide glasses as materials for fiber optics," J. NonCryst. Solids 184, 25-29 (1995).

19. D. Furniss and A. B. Seddon, "Thermal analysis of inorganic compound glasses and glassceramics," in Principles and Applications of Thermal Analysis, P. Gabbott, Ed., pp. 410-449, Blackwell Publishing, Wiley, New Jersey (2008). 
20. A. H. Shabaik, "Differential pressure extrusion through double reduction dies," J. Eng. Ind. 95(3), 890-894 (1973).

21. C. Jiang et al., "Preparation of chalcogenide glass fiber using an improved extrusion method," Proc. SPIE 55(5), 056114 (2016).

22. A. Belwalkar et al., "Extruded tellurite glass optical fiber preforms," J. Mater. Process. Technol. 210(14), 2016-2022 (2010).

23. Z. Xue et al., "Infrared suspended-core fiber fabrication based on stacked chalcogenide glass extrusion," J. Lightwave Technol. 36(12), 2416-2421 (2018).

24. G. Tao et al., "Multimaterial preform coextrusion for robust chalcogenide optical fibers and tapers," Opt. Lett. 37(13), 2751-2753 (2012).

25. thyssenkrupp Materials (UK) Ltd., "Technical data. Stainless steel" (2016).

26. J. D. Shephard et al., "The effect of GaSe on Ga-La-S glasses," J. Non-Cryst. Solids 326-327, 439-445 (2003).

27. A. Ravagli et al., "Optical, thermal, and mechanical characterization of $\mathrm{Ga}_{2} \mathrm{Se}_{3}$-added GLS glass," Adv. Mater. 29(27), 1606329 (2017).

28. H. Suzuki and R. Mori, "Phase study on binary system Ga-Se," Jpn. J. Appl. Phys. 13(3), 417-423 (1974).

29. International Organization for Standardization, "Glass viscosity and viscometric fixed points, in determination of viscosity by beam bending," ISO 7884-4 (1987).

30. C. Vitale-Brovarone et al., "Phosphate glass fibres and their role in neuronal polarization and axonal growth direction," Acta Biomater. 8(3), 1125-1136 (2012).

31. X. Jiang and A. Jha, "Engineering of a Ge-Te-Se glass fibre evanescent wave spectroscopic (FEWS) mid-IR chemical sensor for the analysis of food and pharmaceutical products," Sens. Actuators B 206, 159-169 (2015).

32. Q. Coulombier et al., "Fabrication of low losses chalcogenide photonic crystal fibers by molding process," Proc. SPIE 7598, 759800 (2010).

33. G. Ghosh, "Sellmeier coefficients and dispersion of thermo-optic coefficients for some optical glasses," Appl. Opt. 36(7), 1540-1546 (1997).

34. F. Smektala et al., "Non-linear optical properties of chalcogenide glasses measured by Z-scan," J. Non-Cryst. Solids 274(1), 232-237 (2000).

35. P. Němec et al., "Gallium-lanthanum-sulphide amorphous thin films prepared by pulsed laser deposition," Mater. Chem. Phys. 117(1), 23-25 (2009).

36. G. Lucazeau, S. Barnier, and A. M. Loireau-Lozac'h, "Vibrational spectra, electronic transitions and short order structure of rare earth—gallium sulphide glasses," Spectrochim. Acta Part A 34(1), 21-27 (1978).

37. C. Julien et al., "Raman and infrared spectroscopic studies of Ge-Ga-Ag sulphide glasses," Mater. Sci. Eng. B 22(2), 191-200 (1994).

38. M. Dunleavy, G. C. Allen, and M. Paul, "Characterization of lanthanum sulphides," Adv. Mater. 4(6), 424-427 (1992).

Fernando Guzman is a research fellow at the Optoelectronics Research Centre, Southampton (UK). He received his BS degree in communications and electronics engineering from the National Polytechnic Institute (Mexico) in 2013, and his PhD in optoelectronics from the Optoelectronics Research Centre in 2020. His current research interests include novel glass design and optical fiber manufacturing for passive and active applications. He has been a member of SPIE.

Christopher Craig: Biography is not available.

Bruno Moog is a PhD student at the University of Southampton's Optoelectronics Research Centre. He received his BS degree in physics and biochemistry from the University of Western Australia in 2013 and his MS degree in synchrotron radiation-based science from Lund University in 2017. His current research interests include optical glass and fiber fabrication, with a particular focus on crucible drawing and ultra-thin $<10 \mu \mathrm{m}$ ) fiber.

Andrea Ravagli is a glass developer scientist at Schott AG. He received his $\mathrm{PhD}$ in optoelectronics from the Optoelectronics Research Centre in 2018, where his work was focused in developing a new family of chalcogenide glasses. 
Katrina A. Morgan is a senior research fellow at the Optoelectronics Research Centre and the University of Southampton. She has over 10 years' experience in world-class cleanrooms, developing advanced materials for next generation electronics and photonic devices. Working with academic and industrial partners, her research focuses on wearable and flexible technologies, two-dimensional materials, thermoelectric generators, and resistive memories.

Daniel W. Hewak is a professor of optoelectronics at the University of Southampton, and currently specializes in the production and application of chalcogenide glass for optical and electronic applications. His research is leading to IR fibers for sensing, medical, and aerospace, 2D materials, a new generation of chalcogenide-glass lasers and solar-cell, thermoelectric, display and memory devices. 